\title{
The Relationship Between Sense of Belonging and Student Outcomes in CS1 and Beyond
}

\author{
Sophia Krause-Levy, William G. Griswold, Leo Porter, and Christine Alvarado \\ University of California, San Diego \\ United States \\ \{skrausel,wgg,leporter,calvarado\}@eng.ucsd.edu
}

\begin{abstract}
Students' sense of belonging has been found to be connected to student retention in higher education. In computing education, prior studies suggest that a hostile culture and a feeling of nonbelonging can lead women, Black, Latinx, Native American, and Pacific Islander students to drop out of the computing field at a disproportionately high rate. Yet, we know relatively little about how computing students' sense of belonging presents and evolves (if at all) through their college courses, particularly in courses beyond the introductory level, and little is known about how sense of belonging impacts student outcomes in computing. In an extension of a previous study, we examined students' sense of belonging in six early undergraduate computer science courses across three consecutive quarters at a large research-intensive institution in North America. We found that women and first generation students have a lower incoming sense of belonging across all courses. When exploring sense of belonging's tie to student outcomes we found that lower sense of belonging was correlated with negative course outcomes in terms of pass rates and course performance. We also found that it is less tied to student performance as students get further into the CS curriculum. Surprisingly, there was no indication that sense of belonging is predictive of retention in terms of persistence to the next CS course outside of the first course in our two-course CS1 sequence.
\end{abstract}

\section{CCS CONCEPTS}

\section{- Social and professional topics $\rightarrow$ Computing Education.}

\section{KEYWORDS}

computer science education, sense of belonging, student outcomes, diversity, underrepresentation

\section{ACM Reference Format:}

Sophia Krause-Levy, William G. Griswold, Leo Porter, and Christine Alvarado. 2021. The Relationship Between Sense of Belonging and Student Outcomes in CS1 and Beyond. In Proceedings of the 17th ACM Conference on International Computing Education Research (ICER 2021), August 16-19, 2021, Virtual Event, USA. ACM, New York, NY, USA, 13 pages. https: //doi.org/10.1145/3446871.3469748

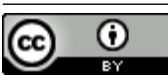

This work is licensed under a Creative Commons Attribution International 4.0 License.

ICER 2021, August 16-19, 2021, Virtual Event, USA

(c) 2021 Copyright held by the owner/author(s)

ACM ISBN 978-1-4503-8326-4/21/08.

https://doi.org/10.1145/3446871.3469748

\section{INTRODUCTION}

Sense of belonging has been shown to be connected to multiple outcomes for college students, including retention, academic standing, and self worth [22, 24, 31]. Specifically in STEM disciplines, research has shown that students from demographics underrepresented in STEM have a lower sense of belonging [6]. While this finding is not necessarily unexpected, it creates a challenge in improving diversity. It may be that students who are unable to see others that look like them feel less like they belong, leading them to drop out of the field, thus continuing their underrepresentation.

In computing specifically, women, Black, Latinx, Native American, and Pacific Islander students are all underrepresented compared to White and Asian men [36]. However, research on sense of belonging in computing is less conclusive than in other STEM fields. When researchers looked at sense of belonging in computing courses, the results varied [11, 26, 32]. Sax et al. [26] recently conducted an extensive study that tried to mitigate this issue by looking at a large population across many universities. They examined students' sense of belonging in computing in introductory computing (CS1) courses across 15 institutions, comparing incoming sense of belonging for different demographic groups and examining how belonging changed from the beginning to the end of the course, as well as trying to understand factors that predict sense of belonging [26]. Their results showed that women have a lower incoming sense of belonging than men, while Black, Latinx, Native American, and Pacific Islander (BLNPI) students had a higher incoming sense of belonging than their majority counterparts, contrary to previous work inside and outside of computing [11,21,33]. Additionally, they found that sense of belonging declines for all students from the beginning to the end of the course, and that this trend is especially pronounced for women [26].

Although the study by Sax et al. is broad and multi-institutional, there is still more to be learned about computing students' sense of belonging. Sax et al. focused on CS1 courses and did not examine the relationship between sense of belonging and student outcomes. A broader understanding of how sense of belonging is related to student outcomes in computing and how it manifests further in the curriculum will help us target our efforts to diversify computing.

In this study we extend Sax et al.'s work on sense of belonging in CS1 to include belonging within subsequent programming courses in the computing curriculum. We further extend prior work by examining the relationship between sense of belonging and retention, both within a course and between courses, as well as how belonging is related to student outcomes, including pass rates, overall course grades and final exam scores. Our results are as follows: 
- Women, first generation (FG), and transfer students have a lower sense of belonging. Consistent with previous findings, our results further demonstrate that women have a lower sense of belonging, not only in CS1 but across the entire lower division curriculum. This gap was also found for first-generation ${ }^{1}$ college students and for transfer ${ }^{2}$ students in some cases.

- BLNPI students do not have a lower sense of belonging. Our results did not find anything to signify that BLNPI students have a consistently lower or higher sense of belonging throughout the curriculum, adding to the mixed results in previous findings.

- Sense of belonging is tied to academic outcomes. This relationship is strongest in introductory CS courses and weakens in more advanced courses.

- Sense of belonging is not tied to between class retention in later classes. We found evidence of a relationship between sense of belonging and retention between classes for non-CS majors in the first course of our two-course CS1 sequence, but found no such evidence for CS majors or for later courses in the curriculum.

- Sense of belonging is tied to pass rate for our twocourse CS1 sequence. Sense of belonging is not tied to pass rate for later courses in the curriculum.

Although our study does not demonstrate a causal link between sense of belonging and outcomes, our results underscore the importance of efforts to improve sense of belonging, particularly for women and first generation students in computing.

\section{PREVIOUS WORK}

Sense of belonging has been shown to be tied to retention, academic standing, self worth, and other positive student outcomes [5, 20, $22,24,31]$. Research inside and outside of computing has shown that sense of belonging is typically lower for underrepresented students in computing, including but not limited to women and BLNPI students, although the results for BLNPI students have not always replicated [6, 7, 11, 17, 19, 21, 26, 28, 30, 33]. Previous studies have also shown that sense of belonging is a distinct factor separate from friendship quality [23] and self-efficacy [35].

\subsection{Sense of Belonging Outside of Computing}

Sense of belonging is related to many aspects of a positive college experience. Work by Pittman et al. has shown that pre-college and early-college sense of belonging is an important factor in the ability of students to successfully adjust to the college experience. In one study, Pittman and Richmond found that students with a higher sense of belonging in high school had better outcomes in college such as higher academic standing and higher self worth [24]. Similarly, Pittman and Richmond surveyed freshman at a university during fall and spring semester and found that incoming sense of

\footnotetext{
${ }^{1}$ First generation students are students who are members of the first generation in their family to attend college.

${ }^{2}$ In our country, it is common for a portion of students to enter university after completing a 2-year college program that fulfills General Education requirements and typically, a couple computing courses. We refer to these students as "transfer" students Typically, transfer students are more socioeconomically diverse than those students entering university directly.
}

belonging was an important factor in students' adjustment during their first year of university, and particularly correlated with quality of friendships and perceptions of social acceptance and academic competence [23]. O'keeffe studied reasons for students dropping out of higher education in their first year and found that a key factor in losing these students was that they were unable to develop a sense of belonging in the institutions [22]. In STEM, Thoman et al. found that a lower sense of belonging leads to a lack of interest in STEM for women and that a stronger sense of belonging in non-STEM fields pulls women away from STEM [31].

While sense of belonging appears to be related to aspects of a successful college experience, a study by Veilleux et al. suggests that it might not (always) be related to STEM students' academic performance. Veilleux et al. surveyed 944 students in STEM across five institutions on their sense of belonging at the course, major, and school level. They found that self-efficacy and expected GPA correlated with students' sense of belonging whereas students' actual reported GPAs were not [32]. This suggests that how students' perceive their ability is more closely tied to their sense of belonging than their actual abilities.

Previous studies have identified factors that have a positive impact on a student's sense of belonging such as having supportive peer relationships, perceiving faculty care about students on an individual level, academic self-efficacy, and motivation [4-6]. Yet, other work suggests sense of belonging is somewhat stable. A multiinstitutional study conducted by Smith et al. researched sense of belonging in engineering at five institutions with respect to their sense of belonging to their course, major, university as an institution and university as a community. Their results did not support the idea that sense of belonging increases as students work their way through a degree in STEM [27].

Finally, there have been multiple studies outside of CS that have shown that women and BLNPI students have a lower sense of belonging than their counterparts [6, 7, 12,30]. Johnson et al. studied the relationship between sense of belonging and the college environment among 2,967 first year undergraduate students in the US. Johnson et al. found that Black, Latinx, and Asian Pacific Americans had a lower sense of belonging than White students [7]. In a later study, Johnson researched the impact of belonging in racially diverse women in STEM and found that race and ethnicity plays a large role in sense of belonging [6].

\subsection{Sense of Belonging in CS}

Likely due to the extremely skewed demographics of computing, many studies of sense of belonging in CS focus on differences between demographic groups, often finding that women, Black, and sometimes Latinx or Asian students have a lower sense of belonging than White men. Nguyen and Lewis studied the survey results of 1,245 first-year students in 80 CS departments. They found that women have a significantly lower sense of belonging than men, and that Black and Latinx students have a significantly lower sense of belonging than their White counterparts [21]. Walton and Cohen found that Black students in computing have a lower sense of belonging, while Lewis et al. found that women have lower sense of belonging than men, and Asian and Black-but not Latinxstudents have lower sense of belonging than White students [11]. A multi-institutional study focused on CS1 by Sax et al. found that 
women had a lower incoming sense of belonging to the course than men, but that the incoming sense of belonging for BLNPI students was similar to that of White and Asian students [26] Stout and Wright found that LGBTQ students were more likely to think about leaving the major due to a lower sense of belonging than their heterosexual counterparts; the same was true of women compared to men [28]. Moudgalya et al. studied student's sense of belonging in introductory computing courses across 21 institutions, with 1165 participants. The results suggest that sense of belonging is correlated with students' interest in taking more CS courses and student's learning outcomes. For Black and Latinx students, sense of belonging was more associated with their interest in pursuing CS, although interestingly sense of belonging was not significantly correlated with a learning assessment used to measure student learning [20]. Blaney and Stout studied the relationship between introductory computing courses experiences and sense of belonging and self-efficacy. They found that first generation women have a statistically significantly lower sense of belonging and self-efficacy compared to their peers [2].

Sax et al.'s work suggests that the relationship between race, gender, and sense of belonging may be more nuanced. They looked at the intersectionality of gender and BLNPI status, finding that BLNPI women had a lower sense of belonging than BLNPI men but a higher sense of belonging than White and Asian women and did not significantly differ from majority men [26]. On the other hand, Mooney and Becker found that the sense of belonging gap between men and women was largely due to women who identify as a minority; women who do not had a sense of belonging similar to men. It was also found that sense of belonging seems to increase for men with prior computing experience but surprisingly not for women and that increased social interactions with other students in computing seems to lead to increased belongingness for all students [17].

There have been several studies in computing aimed at identifying what factors contribute to a student's sense of belonging in computing. Lewis et al. found that students with high communal goals have a lower sense of belonging and that perceiving computing as having affordances for communal goals led to a higher sense of belonging [11]. A study by Cheryan et al. researched the impact of environmental variables on students' feelings of belonging and found that when women are placed in environments that represent stereotypes related to CS they view the environment as masculine and express less interest in CS [3]. Metaxa-Kakavouli et al. conducted a hypothetical study on the impact of the aesthetic features of web interface design for an introductory CS course on sense of belonging in the CS community [15]. They found that women who were presented with the "masculine" course website were negatively impacted across all measures including having a lower sense of belonging and being less interested in enrolling in the course [15].

Experiences can also change computing students' sense of belonging. Mooney et al. found that sense of belonging gaps by gender were reduced for non-minority women who participated in networking, outreach, and mentoring activities. Unfortunately there was no change in sense of belonging for minorities who participated in similar activities [16]. Stout et al. conducted a longitudinal study and found that early formal research experience positively impacted students' sense of mentorship support and in turn mentorship support positively impacted women and BLNPI students' sense of belonging in computing [29]. In a recent study, Mooney and Becker analyzed the impact of COVID-19 on students' sense of belonging and found that COVID-19 had a large impact on students' sense of belonging. There was a statistically significant decrease in sense of belonging for men and surprisingly an increase for women, though this was not statistically significant. Interestingly, men who did not identify as being a part of a minority group had the largest decrease in sense of belonging [18].

\section{STUDY DESIGN}

\subsection{Research Questions}

Our goals with this work were twofold. First, building on Sax et al. [26], we wanted to explore students' sense of belonging in CS1 in a different context and in courses beyond CS1. Second, we wanted to gain a richer understanding of how sense of belonging relates to students' experiences in their first two years of coursework of a CS major. This more complete understanding of belonging and its role in the first two years of a computing program is critical to helping uncover and address systemic biases and barriers that may exist broadly in the program. To achieve these goals, we posed the following research questions:

RQ-1: What do students in lower-division computing courses report as their incoming sense of belonging in computing; and how does this vary by gender, BLNPI, first-generation and transfer-student status?

RQ-2: How does sense of belonging change over time both within a course and across courses as students work through the lower-division computing curriculum; and how does this vary by gender, BLNPI, first-generation and transfer-student status?

RQ-3: Does sense of belonging correlate with student outcomes such as course pass rates, rates of retention between courses, overall course grades and final exam scores in computing courses?

\subsection{Course Context}

We surveyed students in six lower-division undergraduate courses at our university over three quarters: Fall 2019, Winter 2020, and Spring 2020. The COVID-19 pandemic impacted the end of the Winter and all of the Spring 2020 terms. Instruction and exams were in-person until transitioning to online final exams in Winter 2020. Spring 2020 had online instruction and online exams. Each course ran for 10 weeks, followed by a week of final exams. The courses include two introductory programming entry streams: an introductory programming course for students with no experience (CS1) followed by a second introductory programming course (CS1.5), and a single-quarter accelerated introductory programming course comprising all of the material from CS1 and CS1.5 (CS1-Acc). The remaining three courses in the set are a standard basic data structures course (CS2), a computer organization course (Comp Org), and an advanced data structures course (ADS). The ADS course straddles the boundary between lower- and upper-division classes. We did not collect data from ADS in Fall 2019 due to originally only 
looking at lower division programming courses. We began including ADS in Winter 2020 in order to continue collecting data for students continuing on in the program. The typical paths through these courses are shown in Figure 1. Computing majors typically take these courses during their first two years, often in consecutive quarters. Students who transfer from 2-year colleges typically start in CS2, but there is considerable variation: many transfer students start in CS1.5 or CS1-Acc, while another large group starts in Comp Org or ADS.

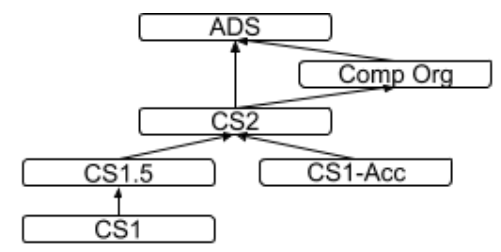

Figure 1: Prerequisite structure for primary identified undergraduate programming prerequisites.

\subsection{Data Collection and Cleaning}

We measured students' sense of belonging throughout the course via a weekly or bi-weekly survey, which was administered as part of each assignment in each course. Sense of belonging questions were embedded in a larger survey designed to measure many aspects of students' experiences in the course (the full survey can be found in Appendix A).

We used a subset of the sense of belonging instrument from Smith et al. [27], which focused on sense of belonging at the class level, as we were interested in students' feelings of belonging in their immediate CS environment (i.e., their classes). Specifically we asked the students "Reflecting on your experiences over the past week, to what extent do you agree with the following statements:". The statements included "I feel accepted in this class.", "I feel comfortable in this class.", "I feel supported in this class.", and "I feel like I don't belong in this class.".

Students rated each statement on a 5-point Likert scale of " 1 (Not at all)”, “2”, “3”, “4”, "5 (Completely)." Ratings were added, with the final statement reverse-coded, to give a total sense of belonging score in the range of 4 to 20 . Previous studies have used a variety of methods to combine the likert scaled ratings, such as summing [26, 27, 30, 32] or averaging [11, 14, 21, 28, 29] the ratings. We chose to sum the ratings because it was consistent with how these questions were aggregated in the original work [27] and to better match the study conducted by Sax et al. that we are expanding upon [26].

We also collected students' overall course grade, final exam score, and demographic information including gender, race/ethnicity, firstgeneration college status, and whether or not the student transferred from another college or university. In the case of race/ethnicity, we were only given access to a binary measure of whether or not students identified as Black, Latinx, Native American, or Pacific Islander (BLNPI) vs. students who identified as White or Asian (Non-BLNPI) to avoid denanonymizing students. When comparing gender, we compared students who identified as women vs. those who identified as men because our university collects only binary Male/Female categories.
Table 1: Number of participants $(\mathrm{N})$ and percentage of Women; Black/Latinx/Native America/Pacific Islander n (BLNPI); Transfer; First-generation (FG) in each course.

\begin{tabular}{|r||r||r|r|r|r|}
\hline Course & $\mathrm{N}$ & Women & BLNPI & Transfer & FG \\
\hline CS1 & 932 & $44.42 \%$ & $19.74 \%$ & $11.16 \%$ & $30.47 \%$ \\
CS1.5 & 624 & $33.65 \%$ & $14.42 \%$ & $8.65 \%$ & $25.00 \%$ \\
CS1-Acc & 863 & $33.95 \%$ & $9.73 \%$ & $11.82 \%$ & $21.90 \%$ \\
CS2 & 1,119 & $28.51 \%$ & $10.19 \%$ & $13.23 \%$ & $21.72 \%$ \\
Comp Org & 934 & $26.34 \%$ & $10.06 \%$ & $18.20 \%$ & $23.23 \%$ \\
ADS & 822 & $25.91 \%$ & $9.49 \%$ & $27.25 \%$ & $22.87 \%$ \\
\hline
\end{tabular}

Sense of belonging scores, overall course grades and final exam scores were all normalized via z-score per course. Normalizing the data is especially important as students sense of belonging may vary by course and in the case of student grades and final exam scores, not all courses or course offerings are equally difficult.

Following our approved Human Subjects protocol, we received data only from students who were 18 or older and who did not opt out of the study, and we limited our data set to only those students who completed the first survey in the course. Table 1 provides a summary of our study population. Participants are counted once for each course they took, so many appear in the population more than once; the total number of unique students is 3,439. For some research questions, we used a subset of the students in our data set, which will be discussed as we present results.

\section{RESULTS}

Using normality tests we found that our data was not normally distributed and therefore we applied non-parametric tests for our analysis. This includes using Mann-Whitney U tests instead of independent sample t-tests, Wilcox signed-rank tests instead of paired t-tests and Spearman correlations instead of Pearson correlations. Due to the large number of statistical tests run during our analysis we adjust our $\mathrm{p}$-values to account for the increased chance of Type I errors. We used the Holm-Bonferroni adjustment method as it reduces the probability of introducing a Type II errors and allows for more statistical power [1]. Additionally, even though our data is non-parametric we chose to visualize our results using average sense of belonging scores per course as displaying averages can be easier to interpret visually than medians.

\subsection{RQ-1: Incoming Sense of Belonging}

Our first research question focuses on understanding sense of belonging early in each course (which we refer to as "incoming sense of belonging") by different group identities including gender, race/ethnicity, first generation status and transfer status. The focus on race/ethnicity and gender mirrors Sax et al.; we added first generation status and transfer status because these are also important at-risk populations in many computing programs. We use data from the first survey given at the beginning of each course as a proxy for sense of belonging at the start of the course (incoming sense of belonging), but we note that because the first survey was linked to the first assignment, students completed this survey about 1-2 weeks into the course which is similar to the time used in Sax et al. [26]. 


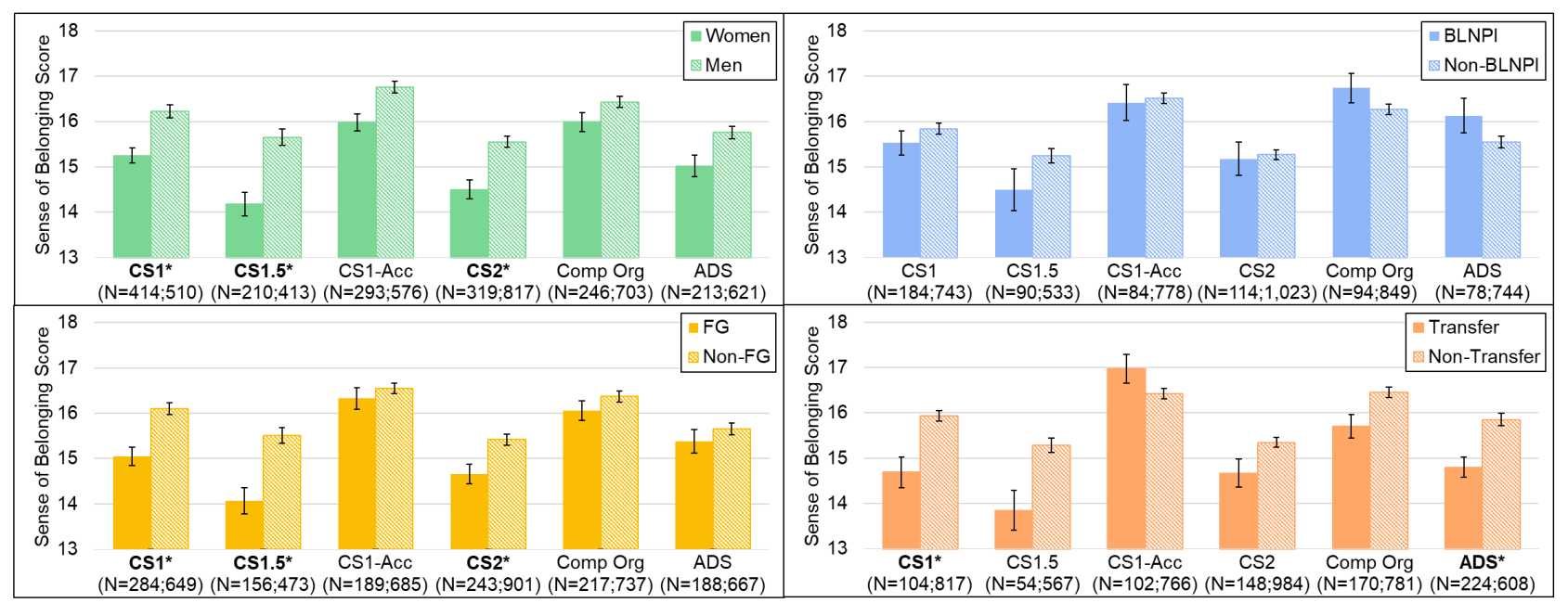

Figure 2: Average incoming sense of belonging scores broken down by demographic groups: Women and Men; Black, Latinx, Native American, and Pacific Islander (BLNPI) and non-BLNPI; First Generation (FG) and non-FG; and Transfer and nonTransfer.

Figure 2 shows the group sense of belonging score averages, by course, and is zoomed into the range between 13-18 (out of 4-20) to help readability. For each demographic pair (e.g. women vs. men) we used a Holm-Bonferroni-adjusted Mann-Whitney U test to test whether the distributions were statistically significantly different in incoming sense of belonging. Courses with statistically significant differences $(\alpha<0.05)$ in sense of belonging for a given group are shown with an asterisk in the $\mathrm{x}$-axis labels in Figure 2 (see Table 2 for results).

Overall, incoming sense of belonging fluctuates between courses, but there is no clear upward or downward trend as students progress through the first two years of coursework. Not surprisingly, students entering the accelerated introductory track (CS1-Acc) seem to have higher sense of belonging than those going through the no-experience track (CS1). Students' incoming sense of belonging seems to dip slightly in CS2, and go up again in later courses.

In terms of group differences, we found the most robust differences by gender and first generation status (Figure 2, top and bottom left). In all courses, women and first generation students had a lower mean and median sense of belonging than their counterparts with the exception of Comp Org for women and CS1-Acc for first generation students, where the medians were equal. The differences in CS1, CS1.5 and CS2 were statistically significant in both cases.

Considering race/ethnicity, we found mixed results (Figure 2, top right). Per course, none of the differences in sense of belonging between BLNPI and Non-BLNPI students were statistically significant, and the direction of difference is not consistent, with BLNPI students having a higher mean sense of belonging in later courses, but lower in the introductory track and CS2. A possible explanation for this is that BLNPI students with lower sense of belonging may not persist to later courses. The median sense of belonging was the same for BLNPI and Non-BLNPI students in all cases.
For transfer students we found that they come in with a lower mean and median sense of belonging except in the case of CS1-Acc (Figure 2, bottom right). We believe a possible reason for transfer students coming into CS1-Acc with a higher mean sense of belonging may be because many transfer students have substantial prior experience, yet are still sometimes required to take CS1 and therefore take the accelerated version. For example, transfer students at our institution sometimes have to retake our CS1 course (in Java) because they took it in a different language at their prior institution. In the later result sections, we'll discuss that this sense of belonging score drops for transfer students (from 17.3 to 15.8) from the beginning to the end of the quarter, whereas it rises for non-transfer students (from 16.5 to 16.6), so this higher sense of belonging for transfer students is unfortunately short-lived.

4.1.1 Intersectionality of Gender and First-Generation Status. Due to the robust differences we found for gender and first generation status, we chose to look at the intersectionality of gender with first generation status to see if the effect is compounded for first generation women. In each course we compared incoming sense of belonging between women and men in the subgroup of first generation and non-first generation students.

We found that first generation women have a lower mean and median sense of belonging than non-first generation women in 5/6 courses. Holm-Bonferroni-adjusted Mann-Whitney U tests showed that the differences were statistically significant for CS1 and CS1.5. First generation men have a lower mean sense of belonging than non-first generation men in $6 / 6$ courses but have a lower median sense of belonging in only $2 / 6$ courses with none of the differences being statistically significant.

First generation women have a lower mean and median sense of belonging than first generation men in $5 / 6$ courses with the differences being statistically significant in CS1 and CS1.5. Non-first generation women have a have a lower mean sense of belonging in $5 / 6$ courses and a lower median sense of belonging in $4 / 6$ courses 
Table 2: Holm-Bonferroni-adjusted Mann-Whitney $U$ test for differences in incoming sense of belonging broken down by demographic groups: Women and Men; Black, Latinx, Native American, and Pacific Islander (BLNPI) and non-BLNPI; First Generation (FG) and non-FG; and Transfer and non-Transfer. star ( $\left.{ }^{*}\right)$ indicates a significant correlation for $\alpha<0.05$.

\begin{tabular}{r|rr|cc|cc|} 
& \multicolumn{7}{|c|}{ Women and Men } \\
& & $N$ & & \multicolumn{2}{c|}{$\begin{array}{c}\text { Incoming Sense of Belonging } \\
\text { Women / Men }\end{array}$} & \multicolumn{2}{c|}{ Mann-Whitney U } \\
& Women & Men & mean & median & $\mathrm{U}$ & $\mathrm{p}$ \\
\hline CS1 & 414 & 510 & $15.3 / 16.2$ & $16.0 / 17.0$ & 89838.0 & $<\mathbf{0 . 0 1}$ \\
CS1.5 & 210 & 413 & $14.2 / 15.7$ & $14.0 / 16.0$ & 34426.0 & $<\mathbf{0 . 0 1}^{*}$ \\
CS1-Acc & 293 & 576 & $16.0 / 16.8$ & $16.0 / 17.0$ & 74601.0 & 0.16 \\
CS2 & 319 & 817 & $14.5 / 15.6$ & $14.0 / 16.0$ & 110568.5 & $<\mathbf{0 . 0 1}^{*}$ \\
Comp Org & 246 & 703 & $16.0 / 16.4$ & $17.0 / 17.0$ & 82048.5 & 1.00 \\
ADS & 213 & 621 & $15.0 / 15.8$ & $15.0 / 16.0$ & 58727.0 & 0.16 \\
\hline
\end{tabular}

\begin{tabular}{r|rr|cc|cc|} 
& \multicolumn{7}{|c|}{ BLNPI and Non-BLNPI } \\
& \multicolumn{2}{|c|}{$N$} & \multicolumn{2}{|c|}{$\begin{array}{c}\text { Incoming Sense of Belonging } \\
\text { BLNPI / Non-BLNPI }\end{array}$} & \multicolumn{2}{c|}{ Mann-Whitney U } \\
& BLNPI & Non-BLNPI & mean & median & $\mathrm{U}$ \\
\hline CS1 & 184 & 743 & $15.5 / 15.8$ & $16.0 / 16.0$ & 66749.0 & 1.00 \\
CS1.5 & 90 & 533 & $14.5 / 15.3$ & $15.0 / 15.0$ & 21516.5 & 1.00 \\
CS1-Acc & 84 & 778 & $16.4 / 16.5$ & $17.0 / 17.0$ & 34181.0 & 1.00 \\
CS2 & 114 & 1023 & $15.2 / 15.3$ & $16.0 / 16.0$ & 57842.5 & 1.00 \\
Comp Org & 94 & 849 & $16.7 / 16.3$ & $17.0 / 17.0$ & 43636.5 & 1.00 \\
ADS & 78 & 744 & $16.1 / 15.6$ & $16.0 / 16.0$ & 31723.0 & 1.00 \\
\hline
\end{tabular}

\begin{tabular}{|c|c|c|c|c|c|c|}
\hline & \multicolumn{4}{|c|}{ FG and Non-FG } & & \\
\hline & \multicolumn{2}{|c|}{$N$} & \multicolumn{2}{|c|}{$\begin{array}{c}\text { Incoming Sense of Belonging } \\
\text { FG / Non-FG }\end{array}$} & \multicolumn{2}{|c|}{ Mann-Whitney U } \\
\hline & FG & Non-FG & mean & median & $\mathrm{U}$ & $\mathrm{p}$ \\
\hline $\mathrm{CS} 1$ & 284 & 649 & $15.1 / 16.1$ & $15.0 / 16.0$ & 76677.0 & $<\mathbf{0 . 0 1}^{*}$ \\
\hline CS1.5 & 156 & 473 & $14.1 / 15.5$ & $14.0 / 16.0$ & 28556.0 & $<0.01^{*}$ \\
\hline CS1-Acc & 189 & 685 & $16.3 / 16.6$ & $17.0 / 17.0$ & 63074.5 & 1.00 \\
\hline $\mathrm{CS} 2$ & 243 & 901 & $14.7 / 15.4$ & $14.0 / 16.0$ & 95763.5 & $<0.01^{*}$ \\
\hline Comp Org & 217 & 737 & $16.1 / 16.4$ & $16.0 / 17.0$ & 75556.5 & 1.00 \\
\hline ADS & 188 & 667 & 15.4 / 15.7 & $15.0 / 16.0$ & 60165.5 & 1.00 \\
\hline
\end{tabular}

\begin{tabular}{|c|c|c|c|c|c|c|}
\hline & \multicolumn{4}{|c|}{ Transfer and Non-Transfer } & \multirow{2}{*}{\multicolumn{2}{|c|}{ Mann-Whitney U }} \\
\hline & & \multicolumn{2}{|c|}{$\begin{array}{l}\text { Incoming Sense of Belonging } \\
\text { Transfer / Non-Transfer }\end{array}$} & & \\
\hline & Transfer & Non-Transfer & mean & median & $\mathrm{U}$ & $\mathrm{p}$ \\
\hline CS1 & 104 & 817 & $14.7 / 15.9$ & $15.0 / 16.0$ & 33927.0 & $<0.01 *$ \\
\hline CS1.5 & 54 & 567 & $13.9 / 15.3$ & $13.0 / 16.0$ & 12264.0 & 0.28 \\
\hline CS1-Acc & 102 & 766 & $17.0 / 16.4$ & $17.0 / 17.0$ & 43529.0 & 0.72 \\
\hline $\mathrm{CS} 2$ & 148 & 984 & $14.7 / 15.4$ & $15.0 / 16.0$ & 68102.5 & 1.00 \\
\hline Comp Org & 170 & 781 & $15.7 / 16.5$ & $16.0 / 17.0$ & 60137.5 & 0.65 \\
\hline ADS & 224 & 608 & $14.8 / 15.9$ & $14.0 / 16.0$ & 56370.0 & $<0.01$ * \\
\hline
\end{tabular}

than non-first generation men with differences in incoming sense of belonging being statistically significant only for CS2.

Given the small populations of some of these subgroups, we do not want to read too much into the results, although this does align with the robust differences we already see for women and first generation students and suggests the effect is compounded for first generation women.

\subsection{RQ-2: Change in Sense of Belonging}

In the previous section, we saw no indication of sense of belonging increasing with courses over time. In this section, we examine the change of sense of belonging both during a single term (start to end) and across multiple terms. 
Table 3: Holm-Bonferroni-adjusted Wilcox signed rank test for differences in incoming sense of belonging in fall and spring broken down by trajectory across quarters. A star $\left(^{*}\right)$ indicates a significant correlation for $\alpha<0.05$.

\begin{tabular}{l|r|cc|rc|} 
& & \multicolumn{2}{|c|}{ Incoming Sense of Belonging } & \multicolumn{2}{|c|}{ Wilcox signed } \\
rank test \\
Course & $N$ & mean & median & z-stat & p \\
\hline Overall & 291 & $16.7 / 16.2$ & $17.0 / 17.0$ & 17935.0 & 0.07 \\
$\mathrm{CS} 1 \rightarrow \mathrm{CS} 1.5 \rightarrow \mathrm{CS} 2$ & 146 & $16.8 / 16.0$ & $17.0 / 16.0$ & 3849.0 & $\mathbf{0 . 0 2}$ \\
$\mathrm{CS} 1 \rightarrow \mathrm{CS} 1-\mathrm{Acc} \rightarrow \mathrm{CS} 2$ & 13 & $16.3 / 15.5$ & $17.0 / 14.0$ & 30.0 & 0.45 \\
$\mathrm{CS} 1-\mathrm{Acc} \rightarrow \mathrm{CS} 2 \rightarrow \mathrm{Comp}$ Org & 65 & $17.9 / 15.9$ & $19.0 / 20.0$ & 790.0 & 0.26 \\
$\mathrm{CS} 1.5 \rightarrow \mathrm{CS} 2 \rightarrow$ Comp Org & 8 & $16.9 / 15.6$ & $17.5 / 20.0$ & 8.0 & 0.45 \\
$\mathrm{CS} 2 \rightarrow$ Comp Org $\rightarrow$ ADS & 59 & $15.2 / 16.3$ & $15.0 / 16.0$ & 694.0 & 0.45 \\
\hline
\end{tabular}

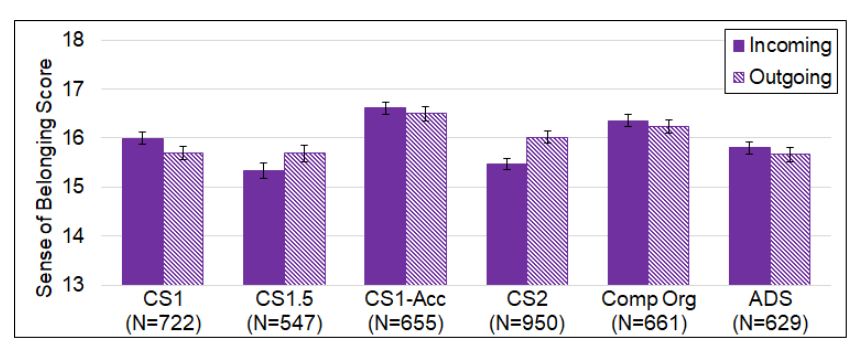

Figure 3: Average incoming and outgoing sense of belonging scores broken down by course for students who completed first and last surveys.

To measure the within-course change in sense of belonging, we used the final survey students completed during the course (completed in or after the final week in the course) to measure their outgoing sense of belonging. For this analysis we include only students who completed the first and last surveys (i.e., a subset of the students used in the RQ1 analysis). Figure 3 shows the incoming and outgoing sense of belonging score averages, by course. We used Wilcox signed-rank tests with a Holm-Bonferroni correction to measure whether there was a change in students incoming and outgoing sense of belongings. As shown in Table 4, none of the differences were statistically significant, and we saw no clear trend in change. We also examined the data by demographic groups as shown in Table 5, but again see no statistically significant differences for any group, and no clear trends. To help provide a broader context, Table 5 provides the mean and median values. However, means and median values can mask changes for individuals. These individual changes are used by the Wilcox signed rank test for determining significance (as shown in Table 5).

4.2.1 Trajectory of Sense of Belonging Across Quarters. We next looked at the trajectory of sense of belonging across quarters. While Figure 2 and Figure 3 show no clear trend in sense of belonging across courses, we thought that the different populations across the courses might be hiding patterns. For this analysis, we used data only from students who took and passed a course in our study in each of the three quarters in our study.

To gain a better sense of student's sense of belonging across quarters we looked at the differences in students' incoming sense of belonging scores. To do this we measured the difference between students' incoming sense of belonging in fall and students'
Table 4: Holm-Bonferroni-adjusted Wilcox signed rank test for differences in incoming and outgoing sense of belonging. A star $\left(^{*}\right)$ indicates a significant correlation for $\alpha<0.05$.

\begin{tabular}{l|c|cc|rc|} 
& & \multicolumn{2}{|c|}{ Sense of Belonging } & \multicolumn{2}{|c|}{ Wilcox signed } \\
Course & $N$ & Incoming / Outgoing & rank test \\
mean & median & z-stat & p \\
\hline CS1 & 722 & $16.0 / 15.7$ & $16.0 / 16.0$ & 118626.0 & 0.20 \\
CS1.5 & 547 & $15.3 / 15.7$ & $16.0 / 16.0$ & 68806.0 & 0.39 \\
CS1-Acc & 655 & $16.6 / 16.5$ & $17.0 / 17.0$ & 103966.0 & 1.00 \\
CS2 & 950 & $15.5 / 16.0$ & $16.0 / 17.0$ & 209314.0 & 0.25 \\
Comp Org & 661 & $16.4 / 16.2$ & $17.0 / 17.0$ & 109254.0 & 1.00 \\
ADS & 629 & $15.8 / 15.7$ & $16.0 / 16.0$ & 93263.0 & 1.00 \\
\hline
\end{tabular}

incoming sense of belonging in spring. We again used a Wilcox signed-rank test with a Holm-Bonferroni correction to measure whether there was a change in students' incoming and outgoing sense of belonging. The results show no statistically significant difference, suggesting no change in sense of belonging (see the first row in Table 3).

Next, we wanted to see if there were any specific sequences of courses where there was a statistically significant difference across courses. The different possible trajectories are as follows:
1. $\mathrm{CS} 1 \rightarrow \mathrm{CS} 1.5 \rightarrow \mathrm{CS} 2(N=146)$
2. $\mathrm{CS} 1 \rightarrow \mathrm{CS} 1-\mathrm{Acc} \rightarrow \mathrm{CS} 2{ }^{3}(N=13)$
3. $\mathrm{CS} 1-\mathrm{Acc} \rightarrow \mathrm{CS} 2 \rightarrow \mathrm{Comp}$ Org $(N=65)$
4. $\mathrm{CS} 1.5 \rightarrow \mathrm{CS} 2 \rightarrow$ Comp Org $(N=8)$
5. $\mathrm{CS} 2 \rightarrow \mathrm{CompOrg} \rightarrow \mathrm{ADS}(N=59)$

We again used a Wilcox signed-rank test with a Holm-Bonferroni correction to determine if there were any significant differences across quarters for each of the possible trajectories. Examining Table 3, we find that the change in sense of belonging was only significant for the trajectory of $\mathrm{CS} 1 \rightarrow \mathrm{CS} 1.5 \rightarrow \mathrm{CS} 2$. The CS1 $\rightarrow \mathrm{CS} 1-$ $\mathrm{Acc} \rightarrow \mathrm{CS} 2$ trajectory had a large decrease in sense of belonging and it may be that due to the small population no statistical significance was found. To gain a better understanding of whether this change was an increase or decrease in sense of belonging we measured the difference between students' incoming sense of belonging from fall to spring and for each student created a binary variable based on whether student's sense of belonging increased or decreased from

\footnotetext{
${ }^{3}$ Although it is not recommended, students are able to take CS1-Acc after CS1 rather than CS1.5.
} 
Table 5: Holm-Bonferroni-adjusted Wilcox signed rank test for differences in incoming and outgoing sense of belonging broken down by demographic groups: Women and Men; Black, Latinx, Native American, and Pacific Islander (BLNPI) and nonBLNPI; First Generation (FG) and non-FG; and Transfer and non-Transfer. A star $\left(^{*}\right)$ indicates a significant correlation for $\alpha<0.05$.

\begin{tabular}{|c|c|c|c|c|c|c|c|c|c|c|}
\hline & \multicolumn{5}{|c|}{ Women } & \multicolumn{5}{|c|}{ Men } \\
\hline & \multirow[b]{2}{*}{$N$} & \multicolumn{2}{|c|}{$\begin{array}{l}\text { Sense of Belonging } \\
\text { Incoming / Outgoing }\end{array}$} & \multicolumn{2}{|c|}{$\begin{array}{l}\text { Wilcox signed } \\
\text { rank test }\end{array}$} & \multirow[b]{2}{*}{$N$} & \multicolumn{2}{|c|}{$\begin{array}{l}\text { Sense of Belonging } \\
\text { Incoming / Outgoing }\end{array}$} & \multicolumn{2}{|c|}{$\begin{array}{l}\text { Wilcox signed } \\
\text { rank test }\end{array}$} \\
\hline & & mean & median & z-stat & $\mathrm{p}$ & & mean & median & z-stat & $\mathrm{p}$ \\
\hline CS1 & 329 & $15.4 / 15.0$ & $16.0 / 15.0$ & 14952.0 & 1.00 & 386 & $16.5 / 16.3$ & $17.0 / 17.0$ & 15717.5 & 0.56 \\
\hline CS1.5 & 180 & $14.4 / 15.3$ & $14.0 / 16.0$ & 2833.0 & 0.51 & 360 & $15.8 / 15.9$ & $16.0 / 16.0$ & 11237.0 & 1.00 \\
\hline CS1-Acc & 233 & $16.1 / 15.7$ & $16.0 / 16.0$ & 5541.5 & 1.00 & 418 & $16.9 / 17.0$ & $17.0 / 18.0$ & 14404.5 & 1.00 \\
\hline $\mathrm{CS} 2$ & 254 & $14.7 / 15.7$ & $15.0 / 16.0$ & 4140.5 & $<0.01^{*}$ & 688 & $15.8 / 16.1$ & $16.0 / 17.0$ & 32079.5 & $<0.01 *$ \\
\hline Comp Org & 185 & $16.1 / 15.8$ & $17.0 / 16.0$ & 3891.0 & 1.00 & 472 & $16.5 / 16.4$ & $17.0 / 17.0$ & 20602.0 & 1.00 \\
\hline $\mathrm{ADS}$ & 165 & $15.2 / 15.1$ & $15.0 / 15.0$ & 3031.0 & 1.00 & 445 & $16.0 / 15.9$ & $16.0 / 16.0$ & 18701.5 & 1.00 \\
\hline
\end{tabular}

\begin{tabular}{|c|c|c|c|c|c|c|c|c|c|c|}
\hline & \multicolumn{5}{|c|}{ BLNPI } & \multicolumn{5}{|c|}{ Non-BLNPI } \\
\hline & \multirow[b]{2}{*}{$N$} & \multicolumn{2}{|c|}{$\begin{array}{l}\text { Sense of Belonging } \\
\text { Incoming / Outgoing }\end{array}$} & \multicolumn{2}{|c|}{$\begin{array}{l}\text { Wilcox signed } \\
\text { rank test }\end{array}$} & \multirow[b]{2}{*}{$N$} & \multicolumn{2}{|c|}{$\begin{array}{l}\text { Sense of Belonging } \\
\text { Incoming / Outgoing }\end{array}$} & \multicolumn{2}{|c|}{$\begin{array}{l}\text { Wilcox signed } \\
\text { rank test }\end{array}$} \\
\hline & & mean & median & z-stat & $\mathrm{p}$ & & mean & median & z-stat & $\mathrm{p}$ \\
\hline CS1 & 132 & $15.6 / 15.1$ & $16.0 / 16.0$ & 2620.5 & 1.00 & 582 & $16.1 / 15.8$ & $17.0 / 16.0$ & 38072.0 & 1.00 \\
\hline CS1.5 & 70 & $14.8 / 15.3$ & $15.5 / 17.0$ & 483.0 & 1.00 & 470 & $15.4 / 15.7$ & $16.0 / 16.0$ & 18739.5 & 1.00 \\
\hline CS1-Acc & 56 & $16.6 / 16.6$ & $17.0 / 19.0$ & 346.5 & 1.00 & 587 & $16.6 / 16.5$ & $17.0 / 17.0$ & 34089.5 & 1.00 \\
\hline $\mathrm{CS} 2$ & 88 & $15.6 / 15.6$ & $16.0 / 17.0$ & 777.0 & 1.00 & 855 & $15.5 / 16.1$ & $16.0 / 16.0$ & 47069.5 & $0.03^{*}$ \\
\hline Comp Org & 59 & $17.0 / 17.1$ & $17.0 / 17.0$ & 325.5 & 1.00 & 591 & $16.3 / 16.2$ & $17.0 / 17.0$ & 34959.5 & 1.00 \\
\hline ADS & 58 & $16.6 / 16.2$ & $16.5 / 16.5$ & 324.0 & 1.00 & 544 & $15.7 / 15.6$ & $16.0 / 16.0$ & 29165.5 & 1.00 \\
\hline
\end{tabular}

\begin{tabular}{|c|c|c|c|c|c|c|c|c|c|c|}
\hline & \multicolumn{5}{|c|}{ FG } & \multicolumn{5}{|c|}{ Non-FG } \\
\hline & \multirow[b]{2}{*}{$N$} & \multicolumn{2}{|c|}{$\begin{array}{l}\text { Sense of Belonging } \\
\text { Incoming / Outgoing }\end{array}$} & \multicolumn{2}{|c|}{$\begin{array}{l}\text { Wilcox signed } \\
\text { rank test }\end{array}$} & \multirow[b]{2}{*}{$N$} & \multicolumn{2}{|c|}{$\begin{array}{l}\text { Sense of Belonging } \\
\text { Incoming / Outgoing }\end{array}$} & \multicolumn{2}{|c|}{$\begin{array}{l}\text { Wilcox signed } \\
\text { rank test }\end{array}$} \\
\hline & & mean & median & z-stat & $\mathrm{p}$ & & mean & median & z-stat & $\mathrm{p}$ \\
\hline $\mathrm{CS} 1$ & 204 & $15.3 / 15.1$ & $16.0 / 16.0$ & 6397.5 & 1.00 & 516 & $16.3 / 15.9$ & $17.0 / 16.0$ & 28664.5 & 0.31 \\
\hline CS1.5 & 131 & $14.3 / 15.0$ & $14.0 / 16.0$ & 1955.0 & $0.02^{*}$ & 415 & $15.6 / 15.9$ & $16.0 / 16.0$ & 13700.5 & 1.00 \\
\hline CS1-Acc & 135 & $16.7 / 16.0$ & $17.0 / 17.0$ & 1623.0 & 1.00 & 518 & $16.6 / 16.6$ & $17.0 / 17.0$ & 25783.5 & 1.00 \\
\hline CS2 & 190 & $14.9 / 15.6$ & $14.5 / 16.0$ & 2258.0 & $<0.01^{*}$ & 760 & $15.6 / 16.1$ & $16.0 / 17.0$ & 39864.0 & $0.03^{*}$ \\
\hline Comp Org & 156 & $15.9 / 16.0$ & $16.0 / 16.0$ & 3011.0 & 1.00 & 503 & $16.5 / 16.3$ & $17.0 / 17.0$ & 22500.0 & 1.00 \\
\hline ADS & 139 & $15.5 / 15.4$ & $15.0 / 16.0$ & 1740.0 & 1.00 & 490 & $15.9 / 15.7$ & $16.0 / 16.0$ & 24339.0 & 1.00 \\
\hline
\end{tabular}

\begin{tabular}{|c|c|c|c|c|c|c|c|c|c|c|}
\hline & \multicolumn{5}{|c|}{ Transfer } & \multicolumn{5}{|c|}{ Non-Transfer } \\
\hline & \multirow[b]{2}{*}{$N$} & \multicolumn{2}{|c|}{$\begin{array}{l}\text { Sense of Belonging } \\
\text { Incoming / Outgoing }\end{array}$} & \multicolumn{2}{|c|}{$\begin{array}{l}\text { Wilcox signed } \\
\text { rank test }\end{array}$} & \multirow[b]{2}{*}{$N$} & \multicolumn{2}{|c|}{$\begin{array}{l}\text { Sense of Belonging } \\
\text { Incoming / Outgoing }\end{array}$} & \multicolumn{2}{|c|}{$\begin{array}{l}\text { Wilcox signed } \\
\text { rank test }\end{array}$} \\
\hline & & mean & median & z-stat & $\mathrm{p}$ & & mean & median & z-stat & $\mathrm{p}$ \\
\hline CS1 & 63 & $15.4 / 14.1$ & $16.0 / 14.0$ & 435.5 & 1.00 & 647 & $16.1 / 15.9$ & $17.0 / 16.0$ & 51123.0 & 1.00 \\
\hline CS1.5 & 42 & $14.1 / 13.8$ & $13.5 / 13$ & 222.0 & 1.00 & 496 & $15.4 / 15.9$ & $16.0 / 16.0$ & 19816.0 & 0.05 \\
\hline CS1-Acc & 75 & $17.3 / 15.8$ & $17.0 / 17.0$ & 318.0 & 1.00 & 576 & $16.5 / 16.6$ & $17.0 / 17.0$ & 30623.0 & 1.00 \\
\hline $\mathrm{CS} 2$ & 105 & $15.1 / 15.2$ & $16.0 / 15.0$ & 1568.5 & $<0.01^{*}$ & 833 & $15.5 / 16.1$ & $16.0 / 17.0$ & 41256.5 & $<0.01^{*}$ \\
\hline Comp Org & 120 & $15.7 / 15.2$ & $16.0 / 15.0$ & 1199.0 & 1.00 & 539 & $16.5 / 16.5$ & $17.0 / 17.0$ & 29354.0 & 1.00 \\
\hline ADS & 154 & $15.1 / 14.7$ & $15.0 / 14.0$ & 2325.5 & 1.00 & 456 & $16.0 / 16.0$ & $16.0 / 16.0$ & 19620.0 & 1.00 \\
\hline
\end{tabular}


Table 6: Logistic regression statistics for the independent variable of sense of belonging and the dependent variable of passing the course. A star $\left(^{*}\right)$ indicates a significant correlation for $\alpha<0.05$.

\begin{tabular}{r|cc|cc|cc|cc|cc|} 
& \multicolumn{2}{|c|}{ CS1 } & \multicolumn{2}{|c|}{ CS1.5 } & \multicolumn{2}{|c|}{ CS1-Acc } & \multicolumn{2}{|c|}{ CS2 } & \multicolumn{2}{|c|}{ Comp Org } \\
Independent Variable & coeff & $\mathrm{p}$ & coeff & $\mathrm{p}$ & coeff & $\mathrm{p}$ & coeff & $\mathrm{p}$ & coeff & $\mathrm{p}$ \\
\hline Sense of Belonging Score & 0.358 & $\mathbf{< . 0 1}^{*}$ & 0.661 & $<\mathbf{0 . 0 1}^{*}$ & 0.162 & 0.13 & 0.263 & 0.08 & 0.202 & 0.05 \\
\hline
\end{tabular}

Table 7: Holm-Bonferroni-adjusted Logistic regression statistics for the independent variables of sense of belonging and demographics and the dependent variable of passing the course. A star $\left(^{*}\right)$ indicates a significant correlation for $\alpha<0.05$.

\begin{tabular}{|c|c|c|c|c|c|c|c|c|c|c|}
\hline \multirow[b]{2}{*}{ Independent Variable } & \multicolumn{2}{|c|}{ CS1 } & \multicolumn{2}{|c|}{ CS1.5 } & \multicolumn{2}{|c|}{ CS1-Acc } & \multicolumn{2}{|c|}{ CS2 } & \multicolumn{2}{|c|}{ Comp Org } \\
\hline & coeff & $\mathrm{p}$ & coeff & $\mathrm{p}$ & coeff & $\mathrm{p}$ & coeff & $\mathrm{p}$ & coeff & $\mathrm{p}$ \\
\hline Sense of Belonging Score & 0.718 & $<0.01^{*}$ & 0.824 & 0.06 & 0.456 & $\mathbf{0 . 0 3}^{*}$ & 0.434 & 0.26 & 0.297 & 0.20 \\
\hline Gender & 2.625 & $<0.01^{*}$ & 1.052 & 0.25 & 4.083 & $<0.01^{*}$ & 3.038 & $<0.01 *$ & 1.973 & $<0.01^{*}$ \\
\hline BLNPI Status & 1.104 & 0.21 & -0.455 & 1.00 & 1.262 & 1.00 & 0.522 & 1.00 & 1.576 & $<0.01^{*}$ \\
\hline FG Status & 1.279 & $<0.01 *$ & -0.059 & 1.00 & 19.900 & 1.00 & -0.354 & 1.00 & 0.995 & $0.02^{*}$ \\
\hline Transfer Status & -0.258 & 1.00 & 2.558 & 0.23 & 1.982 & 0.15 & 0.928 & 0.21 & 0.301 & 1.00 \\
\hline
\end{tabular}

fall to spring quarter. The results show that 146 students in this trajectory (37\%) experienced an increase in sense of belonging and $63 \%$ experienced a decrease in sense of belonging suggesting that students' sense of belonging in the trajectory of CS1 $\rightarrow \mathrm{CS} 1.5 \rightarrow \mathrm{CS} 2$ decreases significantly. As z-scores are a relative measure, we were concerned that using $\mathrm{z}$-scores of sense of belonging might mask changes between quarters, we also ran the above tests without $\mathrm{z}$-scores and the overall results were the same.

\subsection{RQ-3: Belonging and Student Outcomes}

We examined the relationship between students' sense of belonging and four different outcome measurements: pass rates, retention across quarters, overall course grades and final exam scores. We chose to measure pass rates, course grades and final exam scores in order to provide analysis that is comparable to previous studies. In the case of pass rates, this also allows us to look at students who may have dropped the course after taking the first survey.

We included data only from Fall 2019 (which does not contain data for ADS) in this analysis as the COVID-19 pandemic caused changes to our course curriculum at the end of Winter 2020 and all of Spring 2020. These changes affected final exams, and almost certainly affected grades and pass rates. More detailed results on the effects of the COVID-19 pandemic at our university can be found in the paper by Lewis et al. [13].

4.3.1 Pass Rates. We first looked at the relationship between sense of belonging and the likelihood of passing each course. We defined passing as receiving a letter grade of C- or higher. We used logistic regression with Holm-Bonferroni-adjusted p-values where the independent variable was the students' incoming sense of belonging score and a binary measure of whether students passed the course was the dependent variable. We ran this for each course and we found sense of belonging score to be predictive of pass rates for CS1 and CS1.5. The odds ratio for CS1 was 1.43 and 1.94 for CS1.5, meaning that for each point increase in students' incoming sense of belonging score, students were $43 \%$ and $94 \%$ more likely to pass the course. We did not find it to be predictive for CS1-Acc, CS2 and Comp Org (see Table 6).
In addition to running logistic regression with the independent variable of students' incoming sense of belonging we also ran it with the independent variables of sense of belonging, gender, BLNPI, first generation and transfer status with Holm-Bonferroni-adjusted p-values. Here we found that sense of belonging was predictive of passing the course for CS1 and CS1-Acc and gender was predictive of passing the course in all courses except CS1.5. This suggests that sense of belonging is related to passing the course in introductory courses, even when controlling for gender, but also vice versa: there are other factors hindering women's performance in these courses (see Table 7). For all other demographics we saw mixed results.

4.3.2 Retention Across Quarters. It has been shown in previous research that sense of belonging is tied to retention in college overall and in fields outside of computing. In computer science, most studies have been conducted in CS1 [15]. To measure retention across courses, we separated students into two groups: (1) retained students were students who took another CS course in winter or spring and were not repeating a course that they had taken in a previous quarter where they withdrew or received a grade of a D or an F and (2) non-retained students were students who did not take another CS course in winter or spring or were repeating a course that they had taken in a previous quarter where they withdrew or received a grade of a D or an F. We further separated the data into students who are majoring in CS and students who are not, as we would expect non-majors to have different rates of retention as majors. We also ran our analysis excluding students who had to retake a course and saw no changes to the overall findings seen here.

To determine if students' incoming sense of belonging score was predictive of whether the students would continue on in the CS curriculum, we again used logistic regression with Holm-Bonferroniadjusted p-values where the independent variable was students' sense of belonging score and a binary measure of whether students were retained was the dependent variable.

For majors, we found that students' sense of belonging scores were not predictive of student retention for all courses. For nonmajors we found sense of belonging to be predictive of only student 
Table 8: Holm-Bonferroni-adjusted Logistic regression statistics for CS majors for the dependent variable of student retention. A star $\left(^{*}\right)$ indicates a significant correlation for $\alpha<0.05$. Logistic regression was not run on CS1 for CS-majors as too many students were retained to measure any effect.

\begin{tabular}{r|rc|cc|cc|cc|} 
& \multicolumn{2}{|c|}{ CS1.5 } & \multicolumn{2}{|c|}{ CS1-Acc } & \multicolumn{2}{|c|}{ CS2 } & \multicolumn{2}{c|}{ Comp Org } \\
Independent Variable & coeff & $\mathrm{p}$ & coeff & $\mathrm{p}$ & coeff & $\mathrm{p}$ & coeff & $\mathrm{p}$ \\
\hline Sense of Belonging Score & 0.187 & 1.00 & 0.471 & 0.40 & 0.171 & 1.00 & 0.228 & 1.00 \\
Gender & -23.530 & 1.00 & 2.084 & $\mathbf{0 . 0 2}$ & 2.567 & 0.50 & 1.114 & 0.06 \\
BLNPI Status & -23.530 & 1.00 & -0.345 & 1.00 & 1.120 & 1.00 & 1.204 & 0.52 \\
FG Status & -19.700 & 1.00 & 1.970 & 0.25 & -1.277 & 1.00 & 0.615 & 1.00 \\
Transfer Status & 20.406 & 1.00 & 1.658 & 0.52 & 1.461 & 0.26 & -0.273 & 1.00 \\
\hline
\end{tabular}

Table 9: Holm-Bonferroni-adjusted Logistic regression statistics for non-CS majors for the dependent variable of student retention. A star $\left(^{*}\right)$ indicates a significant correlation for $\alpha<0.05$.

\begin{tabular}{r|cc|cc|cc|rc|cc|} 
& \multicolumn{2}{|c|}{ CS1 } & \multicolumn{2}{|c|}{ CS1.5 } & \multicolumn{2}{|c|}{ CS1-Acc } & \multicolumn{2}{c|}{ CS2 } & \multicolumn{2}{c|}{ Comp Org } \\
Independent Variable & coeff & $\mathrm{p}$ & coeff & $\mathrm{p}$ & coeff & $\mathrm{p}$ & coeff & $\mathrm{p}$ & coeff & $\mathrm{p}$ \\
\hline Sense of Belonging Score & 0.350 & $\mathbf{0 . 0 4}^{*}$ & 0.280 & 1.00 & 0.311 & 0.89 & 0.356 & 0.92 & -0.048 & 1.00 \\
Gender & 0.082 & 1.00 & 0.410 & 1.00 & 1.411 & $\mathbf{0 . 0 2}^{*}$ & 1.254 & $<\mathbf{0 . 0 1}^{*}$ & 1.210 & $<\mathbf{0 . 0 1}^{*}$ \\
BLNPI Status & 0.326 & 1.00 & -0.507 & 1.00 & 0.639 & 1.00 & -0.356 & 1.00 & 0.770 & 1.00 \\
FG Status & 0.358 & 1.00 & -1.157 & 1.00 & 1.706 & $\mathbf{0 . 0 4}^{*}$ & 0.210 & 1.00 & -0.334 & 1.00 \\
Transfer Status & -0.473 & 1.00 & -1.436 & 1.00 & 0.409 & 1.00 & -0.172 & 1.00 & -1.650 & 0.18 \\
\hline
\end{tabular}

retention from CS1 into the next course. The odds ratio was 1.42 , meaning that for each point increase in students' incoming sense of belonging score, students were $42 \%$ more likely to be retained. This finding has important implications for recruiting students to the CS major.

Although we found that incoming sense of belonging was not generally predictive of student retention, we were curious to see whether this result might be influenced by the students' demographics. We again used logistic regression, this time also including demographic statuses as additional binary independent variables. The results for CS majors can be found in Table 8 and the results for non-majors can be seen in Table 9. For students majoring in $\mathrm{CS}$ and non-majors we found only gender to be predictive of rates of retention after CS1-Acc, CS2 and Comp Org but surprisingly did not find it to be predictive of retention after CS1 and CS1.5 for either group.

4.3.3 Course Grades. To determine whether incoming sense of belonging is correlated with students' performance we used Spearman's correlation between students' sense of belonging and student's course grades. The correlation coefficients and statistical significance can be seen in Table 10. We found that for CS1, CS1.5 and CS1-Acc and CS2 the results were statistically significant with the correlation coefficient generally decreasing in the later courses. This result suggests that incoming sense of belonging becomes less correlated with student performance in later courses. This is interesting as it suggests that sense of belonging may not be as impactful for student performance as they work their way through the CS curriculum.

4.3.4 Final Exam Scores. We chose to examine final exam scores in addition to overall course grades, as course grade allows for collaboration and awards effort [9]. This allows us to get a better understanding of how sense of belonging may impact students'
Table 10: Spearman correlations with Holm-Bonferroniadjusted p-values between sense of belonging score and course grade. A star $\left(^{*}\right)$ indicates a significant correlation for $\alpha<0.05$.

\begin{tabular}{l|rc|} 
Course & $\mathrm{r}$ & $\mathrm{p}$ \\
\hline CS1 & 0.29 & $<\mathbf{0 . 0 1}^{*}$ \\
CS1.5 & 0.45 & $<\mathbf{0 . 0 1}^{*}$ \\
CS1-Acc & 0.23 & $<\mathbf{0 . 0 1}^{*}$ \\
CS2 & 0.17 & $<\mathbf{0 . 0 1}^{*}$ \\
Comp Org & 0.07 & 0.16 \\
\hline
\end{tabular}

knowledge at the end of the course. The correlation coefficients and statistical significance can be seen in Table 11. We found that for CS1 and CS1-Acc the results were statistically significant with the correlation coefficient decreasing in the later courses. This may be due to those two courses being the majority of students' first computing course at the university. Overall this suggests that course grades are more tied with sense of belonging than final exam scores, although final exam scores do still seem to impact students specifically in introductory courses.

\section{DISCUSSION}

\subsection{Comparison to Sax et al. 2018}

Our study is most similar to the work of Sax et al. Although we did not use precisely the same questions to study sense of belonging in computing (ours were course-based, while Sax et al. asked more generally about belonging in 'computing'), some of our results show similar trends. Yet, we also found results that differed from theirs. Like Sax et al., we found that women consistently have a lower incoming sense of belonging, and this holds even as they work through the lower division courses in the CS curriculum. 
Table 11: Spearman correlations with Holm-Bonferroniadjusted p-values between sense of belonging score and final exam performance. A star $\left(^{*}\right)$ indicates a significant correlation for $\alpha<0.05$.

\begin{tabular}{l|rc|} 
Course & $\mathrm{r}$ & $\mathrm{p}$ \\
\hline CS1 & 0.28 & $<\mathbf{0 . 0 1}$ \\
CS1.5 & 0.25 & 0.09 \\
CS1-Acc & 0.20 & $<\mathbf{0 . 0 1}$ \\
CS2 & 0.14 & 0.11 \\
Comp Org & 0.08 & 0.11 \\
\hline
\end{tabular}

However, we did not find, as Sax et al. did, that BLNPI students came in with a higher sense of belonging than their Non-BLNPI counterparts. Looking across all of the six courses, we found mixed results suggesting that BLNPI students may not always come in with a higher sense of belonging, especially in the earlier courses in the CS program. Additionally, Sax et al. looked into change in belonging over the period of a course and found a decrease overall for students, significant declines for women, and no difference between BLNPI and Non-BLNPI students. We found no trend in change of belonging during a course. This may have been due to our questions on belonging being course-specific, but future work should further investigate how sense of belonging changes throughout a course.

\subsection{Sense of Belonging Development}

Similarly to results in STEM [27], we found nothing to suggest that belonging increases as students progress through their computing courses. The sense of belonging score ranges from 4 to 20. Referring back Table 2 we can see that the mean and median sense of belonging scores do not seem to reach 20 throughout any of the courses. While it is still possible that we are dealing with a ceiling effect, there does still seem to be room for growth for people who feel like they belong.

We are not sure why this is true, but it may simply be that students who stay in computing become more resilient to the same feeling of belonging over time. This idea is supported by the fact that we also found that the relationship between incoming sense of belonging and course performance weakens as students progress through these courses. Perhaps as students progress through a curriculum they rely more on other factors such as self-efficacy rather than on belonging.

Additionally, even in early courses, incoming sense of belonging is predictive of student performance but not of retention outside of some cases in introductory courses, suggesting that it is more predictive of struggle in a course than students' trajectory within computing.

\subsection{Implications}

Our findings confirm prior studies showing that women enter CS with a lower sense of belonging. Concerningly, we see that these feelings do not improve over time, even when the students are in later courses. In addition, we found that these trends are also true for first generation college students. According to situated learning theory, legitimate peripheral participation requires new learners to become full participants in order to master and learn the skill of that community [10]. If students from these groups feel they do not belong, it may be hindering their ability to become full participants and subsequently succeed in the field.

For women, it is not clear whether women feeling like they don't belong is the root of the problem, or rather that their feelings are an accurate representation of their situation. That is, it might not be women's feelings that are hindering their ability to become full participants but instead that cultural messages and acts of exclusion by the people around them are causing the barrier.

Although sense of belonging is distinct from self-efficacy [35], one can imagine how they might influence one another. Moreover, the persistence of a lack of sense of belonging with women may be connected to the recent finding of Rosenstein et al. that showed women experience considerably higher rates of Imposter Phenomenon than men [25]. It could be difficult for a student to feel like they belong if they feel like an imposter. Future work should explore these possible connections.

Although we do not yet know if low sense of belonging is causing the lower performance of these students, this is additional impetus for educators to take action to improve the sense of belonging of their students, particularly for women, transfer, and first generation students.

\subsection{Limitations and Threats to Validity}

Our results are based on course offerings from a single university, which may limit the generalizability of our findings. However, our program follows the ACM Curriculum guidelines [8] and is therefore similar to the curricula used at many institutions.

One threat comes from how and when we measure students' sense of belonging. We focused on students' sense of belonging in a particular course, rather than in the field of computing or program overall, because the course experience is such an integral part of the major and we believed belonging in courses would be more relevant to retention. However, because the questions were specific to belonging in each course, the students' answers may not reflect their sense of belonging in the field or program overall.

There is also the question of whether sense of belonging is simply a measurement of prior CS experiences. Because prior experience is tied to positive outcomes for students in CS [34], we wanted to see if our sense of belonging findings are simply a measure of prior experience as one can imagine having prior experiences in CS might make students feel like they belong in the community more than others who just entered it. Using data on prior CS experiences from a pre-term survey given to our students we used multiple linear regression to create a model predicting final exams scores using the independent variables of prior experience and belonging, and then calculated the r-squared difference of the model. We found that both prior experience and incoming sense of belonging separately contributed to the model suggesting belonging is not simply prior CS experiences. This result, along with prior research $[23,35]$ suggests that sense of belonging is an independent measure of student outcomes. However, sense of belonging may be related to other factors (e.g., peer networks).

Finally, common to many in-program education studies, there was significant variation between different offerings of the same 
course, such as instructor and pedagogical differences, as well as external factors, such as the COVID-19 pandemic and the switch to remote learning in Spring 2020. Additionally, our survey results can show only correlation, not causation. It is not necessarily the case that efforts to increase students' sense of belonging will help with performance or pass rates.

\section{CONCLUSION}

The results of our study have built on prior work and shown that sense of belonging is difficult to change. Women in computing seem to consistently have a lower sense of belonging than men, even after they have made it into their first upper-division course. It is puzzling and somewhat worrisome to see that sense of belonging does not seem to be improving for students in general and more specifically for students that are underrepresented in computing. Fortunately our results do show that sense of belonging becomes less correlated with students' performance in a course as they progress through the program. However, it is concerning that students' sense of belonging upon entry to a course, especially in early computing courses, is predictive of pass rates, final exam scores and course grades. Despite the challenge of changing students' sense of belonging in computing, our study suggests that a stronger focus on women's and first generation students' sense of belonging in computing, especially in early CS courses, is important.

\section{ACKNOWLEDGMENTS}

This material is based upon work supported by the National Science Foundation Graduate Research Fellowship Program under Grant No. DGE-1650112 and NSF Award \#1712508.

\section{REFERENCES}

[1] Mikel Aickin and Helen Gensler. 1996. Adjusting for multiple testing when reporting research results: the Bonferroni vs Holm methods. American fournal of Public Health 86, 5 (1996), 726-728.

[2] Jennifer M. Blaney and Jane G. Stout. 2017. Examining the Relationship Between Introductory Computing Course Experiences, Self-Efficacy, and Belonging Among First-Generation College Women. In Proceedings of the 48th ACM Technical Symposium on Computer Science Education (SIGCSE '17). 69--74.

[3] Sapna Cheryan, Victoria Plaut, Paul Davies, and Claude Steele. 2009. Ambient Belonging: How Stereotypical Cues Impact Gender Participation in Computer Science. Fournal of Personality and Social Psychology 97 (2009), 1045-1060.

[4] Tierra M. Freeman, Lynley H. Anderman, and Jane M. Jensen. 2007. Sense of Belonging in College Freshmen at the Classroom and Campus Levels. The fournal of Experimental Education 75, 3 (2007), 203-220.

[5] Marybeth Hoffman, Jayne Richmond, Jennifer Morrow, and Kandice Salomone 2002. Investigating "Sense of Belonging" in First-Year College Students. Fournal of College Student Retention: Research, Theory \& Practice 4, 3 (2002), 227-256.

[6] Dawn R. Johnson. 2012. Campus Racial Climate Perceptions and Overall Sense of Belonging Among Racially Diverse Women in STEM Majors. Journal of College Student Development 53 (2012), 336-346.

[7] Dawn R. Johnson, Matthew Soldner, Jeannie Brown Leonard, Patty Alvarez, Karen Kurotsuchi Inkelas, Heather Rowan-Kenyon, and Susan Longerbeam. 2007. Examining Sense of Belonging Among First-Year Undergraduates From Different Racial/Ethnic Groups. Fournal of College Student Development 48, 5 (2007), 525542.

[8] Association for Computing Machinery (ACM) Joint Task Force on Computing Curricula and IEEE Computer Society. 2013. Computer Science Curricula 2013: Curriculum Guidelines for Undergraduate Degree Programs in Computer Science.

[9] Sophia Krause-Levy, Sander Valstar, Leo Porter, and William G. Griswold. 2020. Exploring the Link Between Prerequisites and Performance in Advanced Data Structures. In Proceedings of the 51st ACM Technical Symposium on Computer Science Education (SIGCSE '20). 386--392.

[10] Jean Lave, Etienne Wenger, et al. 1991. Situated learning: Legitimate peripheral participation.

[11] Colleen Lewis, Paul Bruno, Jonathan Raygoza, and Julia Wang. 2019. Alignment of Goals and Perceptions of Computing Predicts Students' Sense of Belonging in
Computing. In Proceedings of the 2019 ACM Conference on International Computing Education Research (ICER '19). 11--19.

[12] Karyn L. Lewis, Jane G. Stout, Noah D. Finkelstein, Steven J. Pollock, Akira Miyake, Geoff L. Cohen, and Tiffany A. Ito. 2017. Fitting in to Move Forward: Belonging, Gender, and Persistence in the Physical Sciences, Technology, Engineering, and Mathematics (pSTEM). Psychology of Women Quarterly 41, 4 (2017), 420-436.

[13] Mckenna Lewis, Zhanchong Deng, Sophia Krause-Levy, Adrian Salguero, William G. Griswold, Leo Porter, and Christine Alvarado. 2021. Exploring Student Experiences in Early Computing Courses during Emergency Remote Teaching. In Proceedings of the 2021 ACM Conference on Innovation and Technology in Computer Science Education (ITiCSE '21).

[14] Allison Master, Sapna Cheryan, and Andrew Meltzoff. 2016. Computing Whether She Belongs: Stereotypes Undermine Girls' Interest and Sense of Belonging in Computer Science. Fournal of Educational Psychology 108 (2016), 424--437.

[15] Danaë Metaxa-Kakavouli, Kelly Wang, James A. Landay, and Jeff Hancock. 2018. Gender-Inclusive Design: Sense of Belonging and Bias in Web Interfaces. In Proceedings of the 2018 CHI Conference on Human Factors in Computing Systems (CHI'18). 1--6.

[16] Catherine Mooney, Anna Antoniadi, Ioannis Karvelas, Lána Salmon, and Brett A. Becker. 2020. Exploring Sense of Belonging in Computer Science Students. In Proceedings of the 2020 ACM Conference on Innovation and Technology in Computer Science Education (ITiCSE '20). 563.

[17] Catherine Mooney and Brett A. Becker. 2020. Sense of Belonging: The Intersectionality of Self-Identified Minority Status and Gender in Undergraduate Computer Science Students. In United Kingdom \& Ireland Computing Education Research conference (UKICER '20). 24--30.

[18] Catherine Mooney and Brett A. Becker. 2021. Investigating the Impact of the COVID-19 Pandemic on Computing Students' Sense of Belonging. In Proceedings of the 52nd ACM Technical Symposium on Computer Science Education (SIGCSE '21). $612-618$.

[19] Catherine Mooney, Brett A. Becker, Lana Salmon, and Eleni Mangina. 2018. Computer Science Identity and Sense of Belonging: A Case Study in Ireland. In Proceedings of the 1st International Workshop on Gender Equality in Software Engineering (GE '18). 1--4.

[20] Sukanya Kannan Moudgalya, Chris Mayfield, Aman Yadav, Helen H. Hu, and Clif Kussmaul. 2021. Measuring Students' Sense of Belonging in Introductory CS Courses. In Proceedings of the 52nd ACM Technical Symposium on Computer Science Education (SIGCSE '21). 445--451.

[21] An Nguyen and Colleen M. Lewis. 2020. Competitive Enrollment Policies in Computing Departments Negatively Predict First-Year Students' Sense of Belonging, Self-Efficacy, and Perception of Department. In Proceedings of the 51st ACM Technical Symposium on Computer Science Education (SIGCSE '20). 685--691.

[22] P. O'keeffe. 2013. A Sense of Belonging: Improving Student Retention. College Student fournal 47 (2013), 605-613.

[23] Laura Pittman and Adeya Richmond. 2008. University Belonging, Friendship Quality, and Psychological Adjustment During the Transition to College. Journal of Experimental Education - 7 EXP EDUC 76 (2008), 343-362.

[24] Laura D. Pittman and Adeya Richmond. 2007. Academic and Psychological Functioning in Late Adolescence: The Importance of School Belonging. The Journal of Experimental Education 75, 4 (2007), 270-290.

[25] Adam Rosenstein, Aishma Raghu, and Leo Porter. 2020. Identifying the prevalence of the impostor phenomenon among computer science students. In Proceedings of the 51st ACM Technical Symposium on Computer Science Education (SIGCSE '20). 30-36.

[26] Linda Sax, Jennifer Blaney, Kathleen Lehman, Sarah Rodriguez, Kari George, and Christina Zavala. 2018. Sense of Belonging in Computing: The Role of Introductory Courses for Women and Underrepresented Minority Students. Social Sciences 7 (2018), 122.

[27] Tamara Floyd Smith, Denise Wilson, Diane Carlson Jones, Melani Plett, Rebecca A. Bates, and Nanette M Veilleux. 2012. Investigation of Belonging for Engineering and Science Undergraduates by Year in School. In 2012 ASEE Annual Conference \& Exposition.

[28] Jane Stout and Heather Wright. 2016. Lesbian, Gay, Bisexual, Transgender, and Queer Students' Sense of Belonging in Computing: An Intersectional Approach. Computing in Science \& Engineering 18 (2016), 1.

[29] Jane G. Stout, N. Burçin Tamer, and Christine J. Alvarado. 2018. Formal Research Experiences for First Year Students: A Key to Greater Diversity in Computing? In Proceedings of the 49th ACM Technical Symposium on Computer Science Education (SIGCSE '18). 693--698.

[30] Terrell L. Strayhorn. 2008. Fittin' In: Do Diverse Interactions with Peers Affect Sense of Belonging for Black Men at Predominantly White Institutions? NASPA fournal 45, 4 (2008), 501-527.

[31] Dustin B. Thoman, Jessica A. Arizaga, Jessi L. Smith, Tyler S. Story, and Gretchen Soncuya. 2014. The Grass Is Greener in Non-Science, Technology, Engineering, and Math Classes: Examining the Role of Competing Belonging to Undergraduate Women's Vulnerability to Being Pulled Away From Science. Psychology of Women Quarterly 38, 2 (2014), 246-258. 
[32] Nanette Veilleux, Rebecca Bates, Cheryl Allendoerfer, Diane Jones, Joyous Crawford, and Tamara Floyd Smith. 2013. The Relationship between Belonging and Ability in Computer Science. In Proceeding of the 44th ACM Technical Symposium on Computer Science Education (SIGCSE '13). 65--70.

[33] Gregory M Walton and Geoffrey L. Cohen. 2007. A Question of Belonging: Race, Social Fit, and Achievement. Fournal of Personality and Social Psychology 92, 1 (2007), 82-96.

[34] Brenda Wilson and Sharon Shrock. 2001. Contributing to success in an introductory computer science course: A study of twelve factors. In Proceedings of the 32nd ACM Technical Symposium on Computer Science Education (SIGCSE '01) 184-188.

[35] Denise Wilson, Diane Jones, Fraser Bocell, Joy Crawford, Mee Joo Kim, Nanette Veilleux, Tamara Floyd-Smith, Rebecca Bates, and Melani Plett. 2015. Belonging and Academic Engagement Among Undergraduate STEM Students: A Multiinstitutional Study. Research in Higher Education 56, 7 (2015), 750-776.

[36] Stuart Zweben and Betsy Bizot. 2019. 2019 Taulbee Survey: Total Undergrad CS Enrollment Rises Again, but with Fewer New Majors; Doctoral Degree Production Recovers from Last Year's Dip. 2, 5 (2019).

\section{A SURVEY}

The contents of the survey given to students with the question used in this study in bold.

(1) In the last week, approximately how many hours did you spend outside of class time working on work for this course? (Open text box, numeric answer required)

(2) How challenging was the work for this class this week? (Likert scale: 1-5 where 1 was labeled as "Not at all challenging" and 5 was labeled as "Extremely challenging")

(3) In the past week, which of the following, if any, did you seek help from/work with for this course? (Checkboxes, select one or more)

(a) My peer(s) in this class (as pair programming/joint assignment submission)

(b) My peer(s) in this class (for help completing my own version of the assignment)

(c) My friends who are not in this class

(d) Piazza (I posted one or more questions)

(e) Piazza (I got help from reading responses to others' questions)

(f) A tutor

(g) A TA

(h) The instructor

(i) I did not seek help from anyone this week

(j) Other (Please specify):

(4) In the past week, on a scale of 1 to 5 , to what degree did each of the following interfere with your ability to learn and complete the work for this course? (Likert scale for each item: 1-5 where 1 was labeled as "Not at all" and 5 was labeled as "Significantly")

(a) Requirements for other classes

(b) Illness

(c) Family obligations

(d) Work obligations

(e) Social/personal life issues

(f) Confusion specifically about the assignment

(g) Confusion generally about the material

(h) Getting stuck on a bug

(i) Inability to get help

(j) Embarrassment/discomfort asking others

(k) Self-doubt/lack of confidence

(l) Lack of interest in the assignment or material (m) Goofing off/procrastination

(n) Other (Please specify: )

(5) What is your current overall satisfaction with your performance in this class? (Likert scale: 1-5 where 1 was labeled as "Extremely dissatisfied" and 5 was labeled as "Extremely Satisfied")

(6) Reflecting on your experiences over the past week, to what extent do you agree with the following statements. (Likert scale for each item: 1-5 where 1 was labeled as "Not at all" and 5 was labeled as "Completely")

(a) I feel accepted in this class

(b) I feel comfortable in this class

(c) I feel supported in this class

(d) I feel like I don't belong in this class

(7) At this time, approximately how many other students in this course would you be comfortable reaching out to study with? (Open text box, numeric answer required)

(8) Reflecting on the last week, how stressed have you been overall? (Likert scale for each item: 1-5 where 1 was labeled as "Not stressed at all" and 5 was labeled as "Extremely stressed")

(9) Optional: If you want, please enter any information to expand on or explain your answers to any of the questions on this survey. (Open text box.) 